\title{
A Política de Gestão da Taxa de Câmbio nos anos 90
}

\author{
The Exchange Rate Management Policy in the 1990s
}

RIORDAN ROETT *,*

RESUMO: Os quatro países estudados neste ensaio apresentam as três principais opções de política cambial disponíveis para as nações da América Latina. Esta nota conclui os estudos dando uma perspectiva da discussão.

PALAVRAS-CHAVE: Política cambial; regime cambial; estabilização.

ABSTRACT: The four countries studied in this essay present the three main options of exchange rate policy available for Latin America nations. This note concludes the studies by giving an outlook of the discussion.

KEYWORDS: Exchange rate policy; Exchange rate regime; stabilization.

JEL Classification: F31; F32.

Os ensaios contidos neste livro oferecem uma interessante visão geral dos regimes e políticas cambiais adotados em quatro países latino-americanos: México, Brasil, Argentina e Venezuela. O capítulo de W. Max Corden fornece o arcabouço teórico necessário à compreensão dos dilemas que as autoridades enfrentam na determinação da política cambial, bem como um sumário das possibilidades de escolha política disponíveis: o regime da taxa fixa mas ajustável, o regime da taxa rigidamente fixada e o regime da taxa de câmbio flutuante. Os quatro países aqui analisados foram escolhidos porque representam variações das três opções principais de gestão da taxa de câmbio, em termos tanto da escolha da política quanto do resultado econômico. Uma quarta escolha política - a dolarização - é tratada apenas de passagem neste livro, porque o debate sobre a dolarização ainda é incipiente na América Lati na. As propostas recentemente levantadas pela Argentina e pelo Equador, por exemplo, encontraram pouca receptividade no Departamento

\footnotetext{
* Sarita and Don Johnston Professor of Political Science and Director of the Western Hemisphere Program at Johns Hopkins University -SAIS, Baltimore/MD, United Sates. E-mail: rroett@jhu.edu.

** Texto traduzido por Maria Cristina Godoy.
} 
do Tesouro e no Banco Central dos EUA. ${ }^{1}$ Como sugerem a experiência da União Europeia e a literatura sobre as áreas de moeda ideal, as propostas em favor de uma moeda comum são mais dignas de crédito quando os países em que estão mantêm antigos laços de integração, ou pelo menos laços muito mais fortes do que qualquer um desses países tem agora com os Estados Unidos. ${ }^{2}$

Começando sua análise, Corden discute duas dimensões importantes da política cambial, o método da âncora nominal e o método das metas reais, cada um dos quais com suas vantagens e desvantagens. Para que o método da âncora nominal funcione, são fundamentais a disciplina monetária e a credibilidade do mercado de trabalho. De importância particular para a América Latina, os déficits fiscais não podem ser financiados pela criação de moeda. O método da âncora nominal, no qual a taxa de câmbio serve como âncora para estabilizar a taxa de inflação do país, entrará em colapso na ausência de disciplina fiscal. Em todos os quatro estudos de caso, este desafio foi em geral esmagador.

Uma variação do método da âncora nominal é o uso de uma crawling peg. Utilizar uma peg significa que a velocidade em que a moeda é paulatinamente desvalorizada é predeterminada em um valor menor do que a taxa inicial de inflação; assim, a taxa de inflação dos preços dos bens comerciáveis cairá lentamente. O uso da âncora nominal pode desempenhar um papel crítico na redução da inflação, mas a desvantagem é que o custo do fracasso é muito alto - uma grave perda de reservas cambiais, um aumento do desemprego e uma queda na produção.

No método das metas reais, a taxa de câmbio nominal varia para alcançar metas reais. Mas se houver um choque - um declínio nas relações comerciais, por exemplo - provavelmente será necessária uma depreciação real para melhorar as contas correntes. Sem uma depreciação real, o governo precisaria reduzir drasticamente os gastos, o que poderia levar a uma recessão e a um declínio nas importações. Como Corden ressalta, o uso da taxa de câmbio nominal como um instrumento de política para melhorar as contas correntes esteve no centro dos programas de estabilização da balança de pagamentos do Fundo Monetário Internacional (FMI).

Corden comenta que "A história latino-americana... está atulhada com os cadáveres de regimes cambiais fixos, mas ajustáveis”. Em tais regimes, no entanto, a taxa em geral não é realmente fixa; ao contrário, é utilizada uma crawling peg que se move a uma velocidade predeterminada de desvalorização. Mas o perigo da paridade deslizante é que a desvalorização geralmente é necessária para compensar a valorização real que ocorre ou para responder a um choque adverso - um declínio nos fluxos de capital, por exemplo. Geralmente, a taxa fixa não é totalmente digna de crédito porque sempre existe a possibilidade de desvalorização, caso os fundamentos estejam desalinhados em relação às expectativas do mercado.

\footnotetext{
${ }^{1}$ Dollarization Takes Two Blows Abroad”. Latin American Weekly Report, 2 de março de 1999, p. 101.

2 Ver Robert A. Mundell, “A Theory of Optimum Currency Areas”, American Economic Review, vo. 51 (1961), pp. 657-65.
} 
Como demonstram os quatro estudos de caso, os governos muitas vezes evitam a depreciação, aumentando as taxas de juros, mas há limites para o tempo em que essa opção poderá ser usada com credibilidade para sustentar a taxa. Pelo menos dois dos estudos de caso mostraram também que a confiança na taxa fixa pode declinar de modo bastante rápido. Nesse caso, os governos só têm uma escolha: desvalorizar e passar para a flutuação. Para o governo, as sequelas políticas são muitas vezes tão danosas quanto as duras repercussões econômicas.

Outra opção - usada com moderado sucesso na Argentina desde 1991 - é o regime da taxa de câmbio rigidamente fixada. O currency board da Argentina é uma versão desse método. O grande trunfo do currency board é sua credibilidade, que normalmente é sustentada por uma lei que garante que a política monetária é totalmente determinada pelo nível das reservas cambiais. Assim, os déficits fiscais não podem ser monetarizados, e o Banco Central não pode agir como emprestador de último recurso ao sistema bancário. Esse regime é o que mais se aproxima da completa estabilidade cambial, e garante que a taxa de câmbio seja realmente uma âncora nominal que disciplina a política monetária e coloca em xeque as expectativas inflacionárias.

A principal desvantagem da taxa de câmbio rigidamente fixada, do ponto de vista do país que a adota, é que ela impede o uso do método das metas reais. Diante de um choque adverso, a base monetária deve poder declinar (e as taxas de juros devem poder subir), para que a demanda interna caia e a conta corrente melhore. O risco de uma recessão é alto, a menos que os salários e os preços dos produtos não comerciáveis declinem.

Finalmente, o regime da taxa flutuante é aquele que não tem nenhuma política cambial. O método da âncora nominal pode ser executado por meio da política monetária, como o Brasil está fazendo atualmente. Um desafio-chave para o regime que adota a flutuação é a volatilidade envolvida em resposta à mudança das expectativas. Uma variação do regime flutuante é o regime de flexible peg, no qual o Banco Central estabelece realmente uma taxa, mas é proativo em sua disposição para mudá-la. O Chile empregou essa estratégia durante algum tempo, com sucesso bastante razoável, bem como a Colômbia.

Os quatro estudos de caso demonstram que há poucas certezas no mundo das políticas cambiais. A disciplina fiscal é um ponto crítico para a credibilidade de qualquer taxa, uma lição que a Argentina não havia aprendido até o início de 1991, e que o Brasil só aprendeu - e ainda assim apenas parcialmente - em 1994. A Venezuela continua a ignorar as reais necessidades do ajuste fiscal. O México passou do rápido desenvolvimento para a quebra e de volta para o rápido desenvolvimento e aprendeu as duras lições da rigidez excessiva na política cambial. Tendo em vista a estabilidade da Argentina até o momento, o currency board - sistema de taxa de câmbio fixa - pode continuar tendo algum atrativo, embora a tendência durante a última década na América Latina tenha sido claramente na direção de mais, e não menos, flexibilidade na gestão da taxa de câmbio.

Como escreve Timothy Kessler, foi a desvalorização do peso mexicano, em dezembro de 1994, que pela primeira vez chamou a atenção dos observadores dos 
mercados emergentes para a nova e inesperada volatilidade do mercado global de capitais. Mas o caso mexicano claramente confirma que o impacto do capital internacional é condicionado por políticas e diretrizes internas. As origens da crise começaram com a decisão, em 1987, de ancorar o peso, num esforço para domar a inflação. No início de 1989, foi introduzida uma crawling peg. Mas a inflação do México subiu muito além da inflação dos EUA, e o impacto da crawl deslizante foi uma valorização gradual, porém evidente, do peso.

Embora não faltem explicações plausíveis para a decisão de defender o peso nos anos que antecederam a desvalorização forçada, Kessler está correto em atribuir à política interna a adesão do governo ao regime cambial. As desvalorizações sempre foram um anátema na política mexicana. Embora cada um dos três presidentes anteriores tenha sido forçado a desvalorizar no final de seus mandatos, o presidente Carlos Salinas de Gortari e sua equipe estavam determinados a não fazer isso. As grandes corporações - a espinha dorsal do "sucesso" da Associação Norte-Americana de Livre Comércio (NAFTA) - mantinham altos níveis de endividamento em dólar, e o "pacto social" do México entre as empresas, o governo e a mão-de-obra dependia da manutenção da âncora cambial. Além disso, as classes médias beneficiavam-se da moeda supervalorizada, porque ela ajudava a baixar a inflação e subsidiava o consumo.

Mas no final de 1994, o Partido Revolucionário Institucional (PRI), dominante, só tinha uma opção, a saber: desvalorizar. Apesar dos crescentes déficits comerciais e dos fluxos de capital volátil, o imperativo da corrida presidencial de julho de 1994 - que o PRI ganhou com a eleição de Ernesto Zedillo Ponce de Léon para presidente - e a posse em dezembro desse ano descartaram uma desvalorização imediata. Três semanas depois que o novo chefe do Executivo havia sido empossado, porém, a pressão do peso ficou insustentável, e a nova e inexperiente equipe econômica tomou a decisão de desvalorizar. Seguiram-se recessão, alto desemprego, erosão dos salários e uma queda acentuada nos gastos sociais. A crise do peso forçou o colapso do sistema bancário da nação, exigindo aproximadamente $15 \%$ do produto interno bruto do país para salvá-lo.

No meio da crise financeira, revelações sobre fraudes bancárias proliferaram e o PRI perdeu sua maioria na Câmara Baixa do Congresso. Como se viu depois, o contexto da nova crise econômica pavimentou o caminho para uma política de partidos mais competitiva no México. Na corrida presidencial de 2000, com a candidatura de Vicente Fox, do Partido da Ação Nacional, emergiu um desafio formidável e legítimo para o governo.

O período seguinte à desvalorização e a tentativa do PRI de retomar a supremacia política levaram a uma flutuação favorável do peso, a uma promoção mais agressiva das exportações e a um foco maior na implementação de políticas para promover a posição competitiva do país dentro da NAFTA e em outros mercados internacionais. Além de desencadear os esforços para recapitalizar o sistema bancário e aumentar a transparência das contas públicas, o resultado político da crise do peso foi que a eleição de 2000, sob todos os pontos de vista, foi a eleição mais aberta e limpa da história do país. O México pagou um alto preço pela desvalori- 
zação de dezembro de 1994, mas daquela tumultuada desvalorização emergiram uma economia mais bem monitorada e um sistema político muito mais saudável aparentemente.

O longo caminho até a decisão brasileira de adotar uma âncora cambial em 1994 está claramente explicado no capítulo de Eliana Cardoso. No início dos anos 90, "a inflação tornou-se o mecanismo principal de gerenciamento dos desequilíbrios que os políticos não podiam ou não queriam corrigir". À medida que o Brasil se afastava dos 21 anos de domínio militar, a redução da inflação crônica se tornava a principal ênfase da política econômica. Vários programas de choque heterodoxos foram tentados e falharam; medidas ortodoxas pouco inspiradas foram tomadas e depois abandonadas. Apesar das consequências sociais deletérias da inflação, a economia continuou a funcionar, o que explica em grande parte o motivo pelo qual os esforços iniciais de mudança estrutural falharam.

Em 1993, a pessoa certa - Fernando Henrique Cardoso - tornou-se ministro da Fazenda do Brasil, e ele e seus assessores encontraram urna solução viável: o Plano Real. A estabilização passou por três fases: um ajuste fiscal, uma reforma monetária, e o uso da taxa de câmbio corno âncora nominal. A equipe económica - e o novo presidente, Cardoso, eleito no final de 1994 como resultado do Plano Real - compreendeu a necessidade da reforma fiscal para a manutenção da âncora nominal. Mas o processo de reforma sofreu forte oposição política no fragmentado Congresso brasileiro. O déficit operacional se agravou, assim corno o superávit primário. A liderança econômica recorreu à política monetária corno substituto da reforma fiscal, raciocinando que a reforma fiscal era necessária, mas impossível; portanto, a política monetária teria de bastar até que chegasse o momento político correto para a ação legislativa.

O momento crítico ocorreu com a valorização da taxa de câmbio real, prejudicando o setor industrial e provocando desemprego. Apesar disso, mesmo diante dos crescentes déficits comerciais e da diminuição da poupança, as lideranças políticas achavam difícil resistir ao contínuo uso da taxa de câmbio para manter a inflação sob controle. A chave para o governo foram as fortes entradas de capital, que sustentaram a supervalorização da moeda e ajudaram as autoridades a evitar a realidade sombria.

A hora da verdade para o Brasil veio com a desvalorização na Rússia e a crise da dívida em agosto de 1998. As reservas brasileiras em moeda estrangeira caíram precipitadamente à medida que o governo lutava para defender o real diante de um novo choque externo. Mesmo o inusitado pacote do FMI de US\$ 41 bilhões em dezembro de 1998, destinado a interromper uma quebra ao estilo do México, foi insuficiente. A combinação de incapacidade de agir no campo fiscal com saídas rápidas de fluxos de capital, taxas de juros recordes e incerteza política geral forçaram o governo a adotar um novo regime cambial. Depois de um esforço inicial para controlar a desvalorização, a moeda flutuou.

A desvalorização não foi tão desastrosa como muitos haviam previsto. Em 1999, a confiança dos investidores foi prontamente restaurada pela astuta política monetária e pela tão esperada ação fiscal por parte do Congresso. O governo bra- 
sileiro havia ganhado o tempo necessário para preparar as mudanças estruturais necessárias no futuro para evitar outro ataque especulativo sobre a moeda. O perigo, no caso do Brasil, é que os líderes políticos, como em 1994 e 1995, pensem que as reformas mais profundas não são mais prioritárias, e que a volta do crescimento e a redução das taxas de juros seriam suficientes para sustentar a recuperação. O artigo de Eliana Cardoso destaca os riscos de sucumbir a essa interpretação equivocada das realidades da economia brasileira. Há tempo para agir, mas a vontade política de fazê-lo precisa ser constantemente reavivada para de fato lidar com as tarefas restantes na agenda das reformas.

Os políticos desempenharam um papel-chave na decisão da Argentina de adotar o currency board em abril de 1991. Como comenta Carol Wise, o período de hiperinflação (1989-91) foi o "ponto culminante de quase quarenta anos de má gestão econômica conduzida pelo Estado e de turbulência política". Sem nenhuma alternativa em vista em 1991, o presidente Carlos Menem e o ministro da Economia Domingo Cavallo apostaram no lançamento de um currency board que fixou o peso em um-para-um em relação ao dólar dos EUA. Uma parte importante da aposta foi a credibilidade de Cavallo nos mercados financeiros e a decisão da nova equipe de apressar um profundo programa de reformas do mercado, inclusive redesenhando o sistema fiscal e a liberalização do comércio. Como resultado dessa decisão de 1991, a Argentina entrou em sua mais longa (1991-94) e mais forte expansão desde 1945. A ampla coalizão pela reforma que foi construída sobre esse sucesso econômico, juntam ente com a estabilidade política e econômica representada pelo currency board, ajudaram a garantir a reeleição de Menem em 1995.

De repente, sem aviso, a desvalorização mexicana de dezembro de 1994 desencadeou a enervante onda do "efeito tequila" através da América Latina. Menem e Cavallo reagiram com rapidez. As taxas de juros foram aumentadas, o Orçamento federal foi cortado, o sistema bancário foi reestruturado e os impostos subiram. Mesmo depois que Cavallo se afastou de Menem, em meados de 1996, seu sucessor, Roque Fernández, conseguiu sustentar a taxa de câmbio fixa durante o segundo mandato de Menem na Presidência. Como houve na Argentina a vontade política de avançar com as reformas, as desvalorizações asiáticas de 1997 e o colapso da Rússia em 1998 foram absorvidos sem crises. Seria necessário um terceiro choque sistemático, a desvalorização brasileira de janeiro de 1999, para levantar questões, pela primeira vez na década, sobre a continuidade da execução do currency board. Como a desvalorização do real elevou a taxa de câmbio bilateral do peso em cerca de $18 \%$ em termos reais, o peso do ajuste na Argentina foi abrupto e difícil.

Mas as lembranças da hiperinflação eram fortes. Fernando de la Rúa, o candidato da Aliança Democrática, a coalizão de oposição, e vencedor da eleição presidencial de outubro de 1999, indicou que não haveria alteração da política monetária, embora o presidente Menem tivesse sugerido a possibilidade de dolarização em resposta à desvalorização brasileira. De la Rúa, o candidato de uma nova aliança entre o centro e a esquerda, foi ajudado pela fraca campanha de seu oponente peronista, que sugeriu, num dado momento, que a Argentina deveria pensar numa moratória da dívida. A crescente preocupação com a corrupção, o 
fraco sistema judicial e o desemprego apressaram a derrota dos peronistas nas eleições. Depois da posse, De la Rúa introduziu uma legislação há muito aguardada para controlar as finanças provinciais e desregulamentar os mercados de trabalho internos, o que poderia ajudar a resolver os problemas mais difíceis do país, a saber, a falta de competitividade e a deterioração das rendas e do emprego. Resta verificar se o governo de De la Rúa conseguirá coordenar essas reformas sob as restrições impostas pelo currency board. Como Wise ressalta, a resposta a essa questão reside na capacidade das autoridades de agirem rápido na criação de incentivos que possam aumentar a produtividade e, assim, compensar a valorização da taxa de câmbio dentro de um regime fixo. Com a recuperação econômica no Brasil e nos mercados exportadores tradicionais da Argentina, os ventos econômicos estão mudando de tal modo que a equipe de De la Rúa conseguirá algum espaço de manobra para fazer esses ajustes cruciais.

A Venezuela continua contrastando nitidamente com esses outros países, no sentido de que as autoridades têm evitado a adoção de uma estratégia de mercado, como explica Javier Corrales. Em consequência, a série de choques vindos da Ásia e da Rússia, em 1998, teve resultados terríveis - um aumento agudo da fuga de capitais, acompanhado de volatilidade nos preços mundiais do petróleo. Esses choques foram exacerbados pelo dramático surgimento do risco político, à medida que se aproximavam as eleições presidenciais de dezembro de 1998. As sucessivas pesquisas eleitorais indicavam que o sistema bipartidário que havia governado a Venezuela durante décadas seria derrotado por Hugo Chávez, um antigo oficial militar e um neófito na política, que havia conspirado para derrubar o poder civil em 1992.

A Venezuela caiu numa profunda recessão, o ponto culminante do que Corrales chama de ciclo de reformas "ax-relax-colapse" (corta-relaxa-quebra). No centro desse comportamento padrão está a antiga dependência do país dos rendimentos do petróleo, a ponto de a riqueza nacional continuar a depender dos recursos naturais, e não da produtividade do trabalho ou da competitividade industrial. Quando defrontado com os preços adversos do petróleo em 1998, o governo teve pouca escolha senão cortar os gastos públicos. Quando as contas fiscais atingiram o equilíbrio, a política de austeridade fiscal foi relaxada, mas sem nenhum a reforma profunda das estruturas de impostos e de gastos. Como o a juste fiscal foi meramente cosmético, ele não instilou confiança nos mercados interno e internacional. Seguiuse um colapso já esperado, depois do qual o tenebroso ciclo começou de novo. Esse padrão repetitivo deixou sucessivos governos com um conjunto de problemas não resolvidos que forçaram um declínio permanente nos padrões de vida. A Venezuela ainda precisa conseguir resolver essa dependência de altos e baixos com relação aos preços do petróleo, geralmente chamada de "Dutch disease". ${ }^{3}$

Em 1990, havia flagrantes descontinuidades no processo político da Venezuela. Os movimentos de reforma num setor não eram acompanhados por mudanças

\footnotetext{
${ }^{3}$ W. Max Corden, "Booming Sector and Dutch Disease Economics", Oxford Economic Papers, vol. 36 (1984), pp. 359-80.
} 
complementares em outros setores da economia. Com o agravamento da série de crises, a credibilidade da elite política e do Estado diminuíram. O outrora poderoso sistema de partidos políticos atrofiou-se e chegou perto da implosão, e a política interna chegou a um impasse. Quando a situação se agravou em 1998, os membros do governo discutiram a desvalorização da moeda, mas alguns acreditavam que era melhor deixar essa decisão para o próximo governo. Outros acreditavam que uma desvalorização com credibilidade era algo impossível de conseguir, dada a baixa estima de que o governo gozava, tanto interna como externamente. No entanto, a política de defesa da moeda tinha alguma credibilidade, pois o Banco Central da Venezuela era visto como uma das poucas instituições eficazes do país.

A eleição de Hugo Chávez no final de 1998 abriu um longo e incerto caminho de mudanças políticas institucionais, mas o programa econômico sofreu poucos ajustes concomitantes. A decisão de defender uma taxa de câmbio semi-fixa, em 1998, foi sustentada pelo dramático aumento nos preços do petróleo no final desse ano e durante o ano de 1999. No entanto, problemas estruturais fundamentais permanecem sem solução, e os preços do petróleo estão cada vez mais voláteis. Como alguns observadores salientam, o regime monetário precisa ajustar-se à realidade. Quando ele o fizer, as consequências políticas e econômicas poderão ser severas e polarizadoras.

Os quatro casos examinados no livro confirmam as dificuldades inerentes à escolha e à gestão da taxa de câmbio num contexto internacional de alta mobilidade dos capitais. Apesar das inúmeras tentativas, na literatura sobre política econômica, de especificar o curso político mais eficaz a ser seguido pelas economias de mercados emergentes na escolha de um regime cambial, ainda faltam dados correspondentes sobre desempenho econômico para sustentar qualquer um dos métodos existentes. Esses quatro casos mostraram que a valorização da moeda e o desalinhamento da taxa de câmbio podem ocorrer rapidamente num regime de taxa fixa (Argentina, 1991-95) ou num regime mais flexível (Venezuela, desde 1998). As taxas ancoradas, como as utilizadas no México e no Brasil durante as primeiras fases do ajuste econômico, parecem ter perdido sua lógica assim que o objetivo inicial de redução da inflação foi obtido. Embora a mudança para um regime flutuante em ambos os países tenha determinado o cenário para uma recuperação econômica, em nenhum dos casos se retificou a tendência para um a valorização da taxa de câmbio sob condições de pesadas entradas de capital.

Em suma, esses casos enfatizam até que ponto os resultados de política econômica são, na verdade, condicionados pela política interna e pelo cenário institucional mais amplo. A escolha do regime cambial tem grande importância, mas a recuperação econômica e o crescimento sustentado estão mais inter-relacionados nesses países que seguiram simultaneamente uma política fiscal prudente acompanhada de restrição monetária, e onde as autoridades persistiram na criação de incentivos para aumentar a produtividade e a competitividade. Cada um dos quatro casos oferece conhecimentos valiosos sobre os progressos feitos para coordenar a gestão da taxa de câmbio com essas outras variáveis políticas, e todos eles demonstram que a gestão eficaz da taxa de câmbio numa era de reforma dos mercados ainda 
exige considerável ajuste fino. E, apesar da tendência para uma flexibilidade maior da taxa de câmbio nos países em desenvolvimento, esses casos sugerem que os resultados ainda são incertos. No momento, pode-se dizer que o compromisso político de sustentar o regime cambial escolhido é claramente tão importante quanto o próprio regime. 